\title{
st \\ Autoconhecimento e perspectivas externistas: \\ o compatibilismo em debate
}

Paula Mousinho Martins

\section{Mente, linguagem e significado}

Organização: Waldomiro Silva Filho

Alameda Casa Editorial

São Paulo, 2010, 340 págs.

O livro compõe uma instigante coletânea de textos dos quais - não obstante sua ampla variedade temática, e para salientar apenas seu viés epistemológico - uma das preocupações precípuas é discutir as consequências céticas do externismo em relação ao autoconhecimento. Com efeito, para além do contexto semântico ao qual esteve inicialmente referido, ${ }^{\mathbf{1}}$ o ponto de vista externista cria obstáculos não só para a própria definição de mente, mas também, em sua versão mais radical, para a possibilidade desta última conhecer seus próprios estados intencionais de modo direto, transparente e infalível, tal como sempre defenderam as chamadas "filosofias da consciência" desde Descartes. Essa visão aguda do externismo inviabiliza, portanto, a "autoridade especial" que a primeira pessoa parece intuitivamente deter sobre o conteúdo de seus próprios pensamentos (sejam eles verdadeiros ou falsos), pois põe em xeque a capacidade de atribuirmo-nos e conhecermos de modo privilegiado estados cuja natureza e conteúdo dependem de condições que não podemos conhecer desse mesmo modo. Seguese que, para ter ciência de minhas próprias crenças, desejos ou intenções, necessito da mediação empírica do mundo, já que o conteúdo intencional desses meus estados mentais depende, pelo menos em parte, das relações que estabeleço com o meu meio ambiente natural e social.

Mas isto não é tudo; além de pretender destruir o tradicional reduto autocognoscível da subjetividade, esta nova e desafiadora modalidade de ceticismo também rejeita a suposição de que meus estados intencionais sobrevenham localmente às minhas disposições físicas ou neurais individuais, isto é, sejam determinados por even-

1 O externismo foi defendido explicitamente pela primeira vez por Hilary Putnam (1975). O externismo nasce como uma teoria em semântica filosófica e seu problema principal, como já indica o próprio título do artigo, é a questão da referência e do significado. 
tos do meu cérebro. Se a fisiologia cerebral de fato determinasse minhas ocorrências mentais intencionais, qualquer mudança nessas últimas implicaria mudança neurológica ou cerebral concomitante - mas isto é justamente o que o externismo radical recusa ao supor que elementos exteriores à fisiologia intracraniana possam causar a individuação (e a mudança) de conteúdos mentais intencionais. Logo, a estados cerebrais idênticos ou indiscerníveis nem sempre corresponderão pensamentos e crenças idênticos.

Contestar a autoridade de primeira pessoa, o autoconhecimento e a superveniência mente/cérebro foi justamente o alvo maior de Hilary Putnam ao construir, em 1975, o célebre experimento mental das "Terras gêmeas" para fundamentar sua hipótese de que o significado das palavras "não está na cabeça”. ${ }^{2}$ Putnam lançava, assim, as bases do "externismo natural", segundo o qual a determinação dos conteúdos intencionais depende da estrutura fisico-química "essencial" (não fenomênica) da realidade material a que os atos intencionais se referem. Em outros termos, o sujeito ignorará o conteúdo ou referência das palavras que usa sempre que ignorar a composição molecular das substâncias naturais a que essas palavras se referem. Quatro anos mais tarde, Tyler Burge (1979), apoiando-se igualmente num experimento mental baseado em situação contrafactual, formula as principais características do "externismo social" (que ele preferiu chamar de anti-individualismo). Sua intenção era demonstrar que a individuação dos estados mentais, intencionais ou representacionais do sujeito depende, de um modo constitutivo, não da estrutura material profunda dos objetos como queria Putnam, mas das relações que tal sujeito mantém com seu entorno linguístico e social. Dos experimentos de Putnam e Burge, em todo caso, é possível extrair a mesma conclusão externista de que, se os meios sociais e naturais de cada um deles diferirem, a dois sujeitos dotados de estados psicofísicos indiscerníveis podem ser atribuídos significados e crenças distintos. Da mesma forma, se tais meios vierem a se modificar, os conteúdos ou significados dos pensamentos e crenças dos sujeitos neles inseridos necessariamente também se alterarão.

Burge, entretanto, não vai tão longe quanto Putnam no que tange à refutação do autoconhecimento. Para ele, os juízos do "tipo cogito", isto é, os pensamentos de $2^{\mathrm{a}}$ ordem autoverificáveis devido a sua forma autorreferencial (por exemplo: penso que estou pensando que a água é úmida) são casos inquestionáveis de autoconhecimento privilegiado, de modo que o aspecto externista dos conteúdos mentais deve poder compatibilizar-se com o acesso especial (não empírico, imediato ou direto) que o sujeito tem sobre seus próprios pensamentos, sem que isso todavia implique na adoção do modelo cartesiano. 
Os artigos reunidos no livro Mente, linguagem e significado - organizados pelo editor em seis partes ou eixos temáticos: (1) Anti-individualismo, autoconhecimento e ceticismo; (2) compatibilismo e incompatibilismo; (3) do ponto de vista da primeira pessoa e verdade; (4) conteúdo, referência e normatividade; (5) consequências do antiindividualismo; (6) linguagem e consciência-debruçam-se todos, de um modo ou de outro, sobre os problemas epistemológicos acima mencionados e, nessa medida, posicionam-se no interior da polêmica que há mais de trinta anos divide os compatibilistas e os incompatibilistas em relação à questão do autoconhecimento.

Paulo Faria ("Anti-individualismo e autoconhecimento: uma exposição elementar") inicia a primeira parte meditando, em tom aparentemente simples e pessoal mas que acaba revelando grande complexidade, sobre os paradoxos envolvidos em "se pensar e não se saber o que se está pensando". Se, para saber o que penso quando penso que "há água nos arredores", preciso saber de antemão que se encontram satisfeitas determinadas condições objetivas sem as quais, ao pensar "há água nos arredores", eu não estaria pensando precisamente em água e sim em outra coisa, então de fato não sei o que eu mesmo penso. Entretanto, por que eu deveria supor que o antecedente (há água nos arredores) desse condicional é verdadeiro? Descartada a obrigatoriedade de uma tal suposição, resta que me é dado apenas querer que tal antecedente seja verdadeiro e, a partir de então, estipular a ocorrência de um "fato novo", a ser explicitado por uma nova teoria etc. Dada a inevitável insuficiência do procedimento, o autor nos leva a concluir que a premissa externista incompatibilista em questão não pode determinarse sem dogmatismo. Plínio Junqueira Smith ("Ceticismo e autoconhecimento") fecha a primeira parte mostrando, de modo muito claro e preciso, que um autêntico ceticismo pode perfeitamente aceitar o autoconhecimento e a autoridade de primeira pessoa, desde que coloque em xeque as diversas teorias filosóficas inventadas para explicálos. O exame dessas teorias não mostrará que o autoconhecimento é ilusório, mas sim como é difícil para a razão filosófica explicá-lo satisfatoriamente. A afirmação de que não sabemos o que estamos pensando ou desejando quando pensamos ou desejamos algo parece, de um lado, absurda, pois nega um fato óbvio de nossas vidas, e, de outro, comprometida com pressupostos filosóficos, uma vez que supõe o "externismo" - seja como teoria semântica do significado, seja como teoria de que o conteúdo mental depende do mundo. A inexistência de uma explicação filosófica satisfatória para o autoconhecimento e a autoridade de primeira pessoa não nos leva à conclusão que uma pessoa não sabe o que pensa.

O artigo de Carlos J. Moya ("Reflexões sobre anti-individualismo e autoconhecimento") abre a segunda parte, recordando os dois grandes problemas presentes no debate acerca do compatibilismo: (1) o problema do logro, ou de como conhecer de modo privilegiado conteúdos dependentes de condições que não podem ser conheci- 
das deste modo; e (2) o problema da consequência, ou a aparente (e paradoxal) necessidade de o compatibilista admitir que é possível conhecer a priori proposições (empíricas) sobre o entorno objetivo, dando ensejo a uma inaceitável "redução ao absurdo" do argumento compatibilista. Para o autor, o problema do logro parece a princípio poder resolver-se apelando-se para o "modelo de inclusão" defendido por Davidson, Burge e John Heil. Já o problema da consequência, foco principal do texto de Moya, pode ser enfrentado com êxito pelo compatibilista pela simples razão de que este último não tem por que se comprometer com a indesejada possibilidade de conhecer a priori seu entorno objetivo. O pretenso conhecimento a priori de fatos substantivos sobre o mundo é, na verdade, uma ilusão derivada dos pressupostos fortemente realistas implícitos nos experimentos mentais de Putnam e Burge, e são eles que nos conduzem ao erro de "pressupor o enunciado na conclusão". O pretenso conhecimento a priori de fatos empíricos (a posteriori) nada mais é que o enunciado explícito de estados de coisa que não são a priori senão no sentido de que são pressupostos nos experimentos mentais que levam ao externismo e o sustentam.

No capítulo seguinte, Edgar Marques ("Conteúdo e autoridade da primeira pessoa") analisa o externismo semântico enfatizando uma de suas intuições fundamentais: a postulação de um vínculo entre a determinação da identidade dos objetos dos pensamentos e crenças, por um lado, e a individuação dos pensamentos e crenças acerca desses objetos, por outro. O autor baseia-se em McKinsey (1998) para mostrar a inconsistência da pretensão compatibilista de Burge, que implica a indesejável tese de que fatos empíricos podem ser conhecidos a priori, ou seja, de que o sujeito pode saber a priori coisas relativas ao mundo objetivo pelo simples conhecimento direto dos conteúdos de seus pensamentos e crenças subjetivos. $\mathrm{O}$ argumento de McKinsey aponta para a necessidade de uma delimitação mais precisa do escopo do conteúdo dos pensamentos e crenças que o sujeito conhece a priori - uma estratégia de estreitamento desse conteúdo, a qual, todavia, para Edgar Marques, ainda permanece um tanto obscura. No último artigo da segunda parte, Cristina Borgoni ("Quando externismo e autoconhecimento são compatíveis”) trata da querela do compatibilismo em dois contextos privilegiados: os casos de transferência entre mundos e os argumentos de redução ao absurdo. O objetivo da autora é defender uma posição compatibilista que reconhece algumas exceções. Por um lado, a autora sugere que o incompatibilismo alcançado por meio dos experimentos mentais de transferência entre mundos pode sustentar-se apenas se mantivermos uma visão específica, porém problemática, acerca do autoconhecimento; por outro, o incompatibilismo alcançado por meio dos argumentos do tipo "redução ao absurdo" pode sustentar-se apenas se mantivermos uma visão estreita acerca do externismo. Em outras abordagens, o compatibilismo consegue resistir. Uma boa abordagem do autoconhecimento deve dar espaço tanto ao modo privilegiado 
de sua aquisição, como ao modo indireto e empírico segundo o qual conhecemos parte de nossas mentes. Esse duplo aspecto é ignorado pelo cartesianismo.

Ernesto Perini-Santos inicia o primeiro capítulo ("Da autoridade sobre os próprios atos") da terceira parte observando que o abandono da imagem cartesiana de autoconhecimento, hoje corriqueiro, vem de par com a recusa da assimetria entre o ponto de vista da primeira pessoa e o da terceira pessoa sobre conteúdos de estados mentais. O que talvez não seja ainda tão corriqueiro é a aceitação de que o externismo leve ao abandono dessa assimetria, nem como ele o faria. A intenção do autor é explorar a conexão entre o domínio que o sujeito tem das próprias atitudes proposicionais e a estrutura da proposição apreendida. Nesse sentido procede à consideração de casos que evidenciam que o sujeito de fato domina um aspecto crucial de seus próprios estados mentais para, em seguida, isolar, na estrutura proposicional, este elemento sobre o qual não parecem se exercer pressões externistas. A teoria sobre a estrutura de proposições proposta pela semântica de situações é, em mais de um aspecto, compatível com essa assimetria na apreensão de elementos do que é avaliado como verdadeiro ou falso. O objetivo de Perini-Santos não é, contudo, argumentar em favor de uma tal semântica, mas ver como um traço da apreensão de proposições parece ser particularmente bem acolhido nesse quadro teórico. O segundo capítulo da terceira parte, de Hilan Bensusan ("Da primeira pessoa, porém não pessoal: pensando de re sobre si mesmo"), considera falsa a tese de David Chalmers (1996) segundo a qual há partes do mundo que são indexicais "até a medula", não podendo ser acessadas senão em primeira pessoa. A tese de Chalmers interessa apenas na medida em que veicula a ideia de que o mobiliário do universo contém itens indexicais - que são posicionais sem serem "projeções de um sujeito". Isto leva o autor a explorar, ainda que brevemente, a possibilidade de tais itens serem não subjetivos, isto é, não pessoais. Ele proporá a hipótese de um "eu mínimo" no qual a identidade pessoal não está pressuposta e deve ser, antes, produto de uma "conquista". Não haveria em pensamentos e estados atribuídos a mim mais do que um eu que os agrega e compõe. Não tendo mais a identidade pessoal como suposição de base, o eu mínimo não constituirá um sujeito da dor, do medo ou da crença, ou seja, não comporá o constituinte inarticulado de expressões tais como "dói meu braço", "dou-me conta da crença de que faz sol" etc. Nessa tese subsidiária à de Chalmers, portanto, o acesso à primeira pessoa pode ser levado a sério sem se pressupor uma tal primeira pessoa. O texto "Expressivismo, verdade e conhecimento", de Alexandre N. Machado, conclui a terceira parte, argumentando que na medida em que, para o "expressivismo simples", as "manifestações" (frases na primeira pessoa do singular com verbo psicológico no presente do indicativo que, quando pronunciadas sinceramente, veiculam autoconhecimento) não são apofânticas, é errado atribuir "expressivismo simples" a Wittgenstein. O caráter deflacionista do expressivismo 
wittgensteiniano permite manter o caráter apofântico das manifestações, já que dizer que uma frase é verdadeira ou falsa não implica nenhuma "tese epistêmica” específica sobre ela (não implica dizer que esse tipo de frase é de natureza cognitiva, isto é, potencial veiculadora de conhecimento). $\mathrm{Na}$ crítica ao neoexpressivismo de Bar-On e às teorias epistêmicas do autoconhecimento, Machado encontra razões para pensar que as manifestações não são mesmo cognitivas, e nesse caso o expressivismo de Wittgenstein parece superior ao neoexpressivismo, mantendo vivo o desafio deflacionista. Mas isto não significa dizer que o expressivismo de Wittgenstein é a melhor abordagem acerca das manifestações: ele também tem problemas, como o fato de não haver expressão natural para certos estados mentais.

Roberto Horácio de Sá Pereira inaugura a quarta parte com o artigo intitulado "O conteúdo exíguo segundo uma ótica anti-individualista", no qual examina a legitimidade dos chamados "conteúdos exíguos" em filosofia da mente. O objetivo do autor é defender uma concepção de conteúdo exíguo segundo uma ótica anti-invidualista que, embora rejeite a suposição tradicional de que leis intencionais tenham que ser formuladas em termos de conteúdo exíguo, está convencida da importância de tais conteúdos para a explicação da conduta. De acordo com essa leitura, enquanto o conteúdo amplo da ocorrência mental "água” constitui a propriedade semântica de tal ocorrência de representar de dicto $\mathrm{H}_{2} \mathrm{O}$ como água, o conteúdo exíguo da mesma ocorrência mental constitui a propriedade semântica alternativa de tal ocorrência de representar de dicto tanto $\mathrm{H}_{2} \mathrm{O}$ como XYZ como substância aquosa em todos os indivíduos indiscerníveis a respeito de alguma propriedade neurológica relevante dos seus cérebros. No segundo capítulo, Jônadas Techio ("Anti-individualismo, autoconhecimento e responsabilidade") tem por objetivo proceder a uma espécie de resgate das raízes linguísticas do anti-individualismo, pois, apesar de este pretender ser uma teoria da mente, a argumentação anti-individualista depende de um modelo particular de normatividade. A análise estará concentrada num único aspecto da posição anti-individualista que o autor considera problemático: a adoção do modelo impessoal de normatividade linguística, segundo o qual o fundamento de nosso acordo sobre o significado de nossos termos ou frases encontra-se no conhecimento (impessoal) de um conjunto de "fatos objetivos". A identidade desse conjunto de fatos varia de autor para autor, mas a suposição de que o ônus da correção linguística (daquilo que o sujeito quer dizer com o que diz) incide sobre algum fator externo (tal como o mundo ou as convenções da comunidade) é assumida por todos os anti-individualistas. Para Techio, isto significa uma inversão no próprio modo de conceber o problema da correção linguística, cuja consequência imediata é retirar do sujeito individual, participante da comunidade linguística, a responsabilidade em dar sentido a suas próprias palavras e às palavras dos demais e, assim, fornecer condições para um acordo. O principal interesse do ca- 
pítulo é esboçar uma imagem alternativa para se pensar a linguagem humana e a normatividade linguística, que esteja livre dos problemas do modelo impessoal adotado pelos anti-individualistas (mas também assumido por seus críticos) e, particularmente, do tipo de evasão que ele acarreta.

No último capítulo da quarta parte, Carlos E. Caorsi ("O argumento de Kripke sobre a linguagem privada: uma perspectiva davidsoniana”) recupera a reconstrução kripkeana do argumento de Wittgenstein contra a linguagem privada, segundo o qual falar uma linguagem é seguir um determinado conjunto de regras - entendendo por regra aquilo que dá significado a uma palavra por determinar o modo como esta deverá ser usada. Wittgenstein nega o "modelo privado" do que é seguir uma regra, porque esse ato não pode ser analisado em termos de fatos acerca de quem segue a regra e só dela: a referência à sua condição de pertencer a uma comunidade mais ampla é necessária. Kripke considera, todavia, que o caráter normativo da linguagem está dado pela comunidade de fala, e nisto ele se equivoca, pois quem realiza a interpretação do falante não é uma tal comunidade, conceito demasiadamente abstrato, e sim os intérpretes concretos. Para Caorsi, o que conta para a comunicação não é o falante e o intérprete usarem as mesmas regras, mas que o falante use as palavras como o intérprete esperaria usá-las. Se a situação é de "interpretação radical” (nos termos de Davidson), a expectativa do intérprete com respeito ao uso do falante dependerá dos usos anteriores da palavra por parte do falante que foram observados pelo intérprete. E o que determinará ao falante falar do modo que o faz será sua intenção de ser interpretado pelo intérprete, não sua intenção de seguir alguma regra em particular que o intérprete também segue. A intenção do falante é usar as palavras do modo que supõe poder o intérprete entendê-las.

A quinta parte inicia-se com o texto de César S. dos Santos ("Exilados da terra Gêmea: os experimentos mentais e a natureza da intencionalidade”), onde se busca caracterizar minimamente o que é um experimento mental e mostrar a estrutura dos principais experimentos mentais presentes nos debates sobre o externismo. Além disso, o autor procura avaliar se esses experimentos mentais foram bem construídos e aplicados, chegando à conclusão que a construção e a aplicação dos mesmos está em perfeita ordem. No capítulo seguinte, Waldomiro Silva Filho ("Deflacionando o antiindividualismo") expõe duas idéias, encontradas em Gary Ebbs (1996), que lhe pareceram promissoras no debate sobre o anti-individualismo e o autoconhecimento: a interpretação deflacionista do anti-individualismo de Putnam e Burge e um tratamento minimalista do autoconhecimento. Com a primeira, Ebbs pretende desfazer a impressão equivocada de que o anti-individualismo pressupõe teses metafísicas acerca da natureza da relação das nossas mentes com o entorno. Seu deflacionismo é uma forma de antiessencialismo e uma crítica ao realismo metafísico e científico. Tudo o que o 
anti-individualismo requer é nossa perspectiva como participantes de uma comunidade de praticantes - comuns ou científicos - de uma linguagem. Quanto ao autoconhecimento, dado que para Ebbs o conhecimento é um aspecto trivial da competência no uso de uma linguagem, o único requisito para que um sujeito conheça os conteúdos dos pensamentos que expressa com nossas frases é estar habilitado a usar essas frases em discursos, realizar e avaliar asserções próprias e dos outros, fazer questões, descrever possibilidades, esclarecer confusões etc. A mesma atitude que nos leva a atribuir crenças e pensamentos a um indivíduo também mostra que ele conhece o conteúdo daqueles pensamentos e crenças.

No último capítulo da quinta parte, André Leclerc ("Do externismo ao contextualismo") analisa a mudança mais recente na trajetória filosófica de Hilary Putnam: o momento em que este abraça o contextualismo, passando a ser um dos maiores críticos do funcionalismo que ele mesmo havia lançado. A principal tese contextualista é a de que o conteúdo de nossas enunciações, "o que é dito", depende de vários fatores contextuais, e que exemplares (tokens) da mesma frase (type) podem determinar, em ocasiões diferentes, conteúdos vero-condicionais diferentes ou expressar diferentes proposições (ou pensamentos). Embora essa posição já possa ser encontrada em Putnam (1975), Leclerc mostra de modo bastante competente que o externismo não leva diretamente ao contextualismo, pois podemos chegar a este último a partir de uma posição claramente incompatível com o externismo.

Dando início à última parte do livro, João Vergílio Gallerani Cuter reflete sobre a questão dos conteúdos perceptivos que parecem ser independentes de nossas capacidades conceituais e, portanto, nos serem dados independentemente de nosso domínio linguístico. Como não só animais, mas também recém-nascidos são “cegos” para o aspecto conceitual de suas próprias percepções, o autor acredita que os conteúdos não conceituais foram abandonados em algum ponto de nossa trajetória, mais especificamente, perdemos acesso a eles a partir do momento em que aprendemos a falar. A conclusão é que ao aprender a falar ficamos cegos para objetos desvinculados de qualquer determinação, e isto significa que perdemos a memória dos objetos que ainda não podíamos identificar como isto ou aquilo. Fechando a sexta parte e finalizando o volume organizado por Waldomiro Silva Filho, Marco Rufino ("Constituintes proposicionais inarticulados") debruça-se sobre os dois tipos de expressão linguística que se distinguem por seu mecanismo de significação: as chamadas "expressões eternas" (cuja extensão, uma vez fixadas suas regras de uso, não muda de acordo com o contexto de enunciação), e as "expressões indexicais" (cuja extensão e intensão podem mudar de contexto para contexto por força de suas próprias regras de uso; por exemplo: aqui, agora, hoje, este, eu etc.). Dado que os diferentes elementos da proposição expressa por uma sentença são valores semânticos de elementos gramaticalmente distintos pre- 
sentes na sentença, há objetos e propriedades que correspondem a expressões eternas, assim como há objetos e propriedades que correspondem a expressões indexicais. Como a estrutura da proposição espelha a estrutura gramatical da sentença, a forma geral pela qual a linguagem funciona é a de que conteúdos não linguísticos sempre refletem a estrutura gramatical dos elementos linguísticos. John Perry $(1986,1998)$ chamou tal concepção de homomórfica e colocou-a em questão, considerando que há alguns casos em que a proposição expressa por uma sentença inclui algum elemento que não é o valor semântico de nenhuma expressão eterna ou indexical (ou seja, nenhum morfema). Rufino analisa não só a posição de Perry, mas também a de Stanley, Cappelen, Lepore e Recanati, concluindo que não há ainda uma posição satisfatória quanto aos constituintes inarticulados, seja para integrá-los em uma teoria semântica coerente, seja para fazê-los desaparecer de vez da mesma.A

\section{Paula Mousinho Martins \\ Centro de Ciências do Homem,}

Laboratório de Cognição e Linguagem, Universidade Estadual do Norte Fluminense Darcy Ribeiro, Campos dos Goytacazes, Brasil. pmartins@uenf.br

\section{Self knowledge and external perspectives: a debate on compatibilism}

\section{REFERÊNGIAS BIBLIOGRÁFIGAS}

Burge, T. Individualism and the mental. In: French, P. A.; Uehling Jr., T. E. \& Wettstein, H. K. (Ed.). Studies in metaphysics. Minneapolis: University of Minnesota Press, 1979. p. 73-121.

Chalmers, D. The conscious mind: in search of a fundamental theory. Oxford: Oxford University Press, 1996.

Еввь, G. Can we take our words at face value?. Philosophy and phenomenological research, 56, p. 499-53о, 1996.

French, P. A.; Uehling Jr., T. E. \& Wettstein, H. K. (Ed.). Studies in metaphysics. Minneapolis: University of Minnesota Press, 1979. (Midwest Studies in Philosophy, v. 4).

Gunderson, K. (Ed.). Language, mind and knowledge. Minneapolis: University of Minnesota Press, 1975. (Minnesota Studies in the Philosophy of Science, v. 7).

McKinsey, M. Anti-individualism and privileged access. Analysis, 51, p. 9-16, 1998.

PERRY, J. Thought without representation. Supplementary Proceedings of the Aristotelian Society, 6o, p. 263 83, 1986.

. Myself and I. In: Stamm, M. (Ed.). Philosophie in synthetischer Absicht. Stutgard: Klett-Cotta, 1998. p. 83-103.

Putnam, H. The meaning of "meaning”. In: Gunderson, K. (Ed.). Language, mind and knowledge. Minneapolis: University of Minnesota Press, 1975. p. 131-93. 